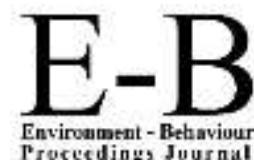

Procecding, Juurnal

\section{AicE-Bs2019Lisbon}

https://www.amerabra.org; https://fspu.uitm.edu.my/cebs; https://www.emasemasresources.com 9th Asia Pacific International Conference on Environment-Behaviour Studies, Faculty of Architecture, Ulisboa, Lisbon, Portugal, 03-04 Jul 2019

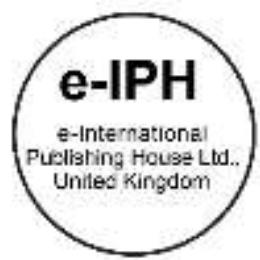

\title{
The Importance of Interior Architecture to Meet Residents' Needs in Gated Communities in Cairo
}

\author{
Karam Abdallah \\ Interior Design Department, Faculty of Art and Design, \\ October University for Modern Sciences and Arts, Egypt \\ kabdallah@msa.eun.eg \\ Tel.: 00201224954175
}

\begin{abstract}
The city of Cairo - since the beginning of the third millennium - has witnessed a constructional expansion of new cities for people of class A to live within gated communities, which provide luxury and safety. This research aims to identify the tangible and intangible needs from the occupants' and the interior designer's perspective, due to the diversity of these needs. The identification of these demands may help to clarify the requirements provided by the large construction companies, which will highlight the role of the interior designer in the design process of the residential units.
\end{abstract}

Keywords: Interior design in Egypt, Contemporary Egyptian residences, Egyptian residential needs, Gated communities in Egypt.

eISSN: 2398-4287@ 2019. The Authors. Published for AMER ABRA CE-Bsby e-International Publishing House, Ltd., UK. This is an open access article under the CC BYNC-ND license (http://creativecommons.org/licenses/by-nc-nd/4.0). Peer-review under responsibility of AMER (Association of Malaysian Environment-Behaviour Researchers), ABRA (Association of Behavioural Researchers on Asians) and cE-Bs (Centre for Environment-Behaviour Studies), Faculty of Architecture, Planning \& Surveying, UniversitiTeknologi MARA, Malaysia.

DOI: https://doi.org/10.21834/e-bpj.v4i11.1727

\subsection{Introduction}

After the controversy over architectural theories in the last century, the importance of the relationship between human needs and the interior architecture was noticed. Therefore, interior architecture is the closest type of art to man, as it requires dealing with man daily (Wahbe, 2011, 110). "Building grows from inside outward" became a fact that architects should deal with, so the interior spaces should not be compressed randomly in prearranged blocks, and the façade should become a cover for internal spaces (Samy, 1968). Thus, the actual role of interior architecture is to study the layout of the building before designing the facade to fulfill the occupants' functional and psychological needs, and the interior designer plays this role. Recently, architectural and construction companies have been interested in designing façades and landscapes of residential gated communities harmoniously. This is accompanied by a dominating economic side that aims to gain a large profit by building as many residences in the available space as possible, at the expense of the interior architecture of the residential units. Interior spaces are subject to various imperfections, due to the link between them with the façades and building area. It is supposed that high income residential architecture should meet the various needs of occupants who are often forced to make significant architectural adjustments, not to please their personal desires, but to change basic functional needs related to spaces' arrangements and circulation. This study includes Egyptian class A occupants, living in GCs in Sheikh Zayed, $6^{\text {th }}$ of October City. The study's time framework covers the beginning of the $21^{\text {st }}$ century until 2019.

\subsection{Issues}

This research deals with the problem of the lack of studies that: a) show the opinion of class A contemporary Egyptian occupants, with regard to their residential units, and b) determine the occupants' tangible and intangible needs, from the their point of view. This problem may be a result of the misunderstanding of the interior designer's role during the design process in the Egyptian construction companies; this causes many mistakes in the layout of residential units. Therefore, the question is: Do the constructional companies 
cover all the occupants' needs? The residents' questionnaire may answer this question, while simultaneously pointing towards the residents' preferences, which will help create a better design solution. The search hypothesis is that the interior designer has no role in providing the occupants' needs, and his role is confined to decoration, furnishing suggestions, and finishing the pre-established unit. The dissatisfaction of the occupants with their residences will confirm his weak participation in the design process from the start.

\subsection{Aim}

The research aims to identify the tangible and intangible needs from the occupants' and the interior designer's perspectives. To reach the following objectives: a) find the occupants' preferences (derived from their opinions and design principles) regarding residential interior architecture, b) use these preferences to help the companies design high-income residential units, and c) highlight the importance of the interior designers' participation in the design process.

\subsection{Literature Review}

\subsection{Importance of the interior designer}

Some research discusses the importance of the interior designer from the architect's perspective. This perspective differs from the interior designer's perspective, who takes care not only of the finishing, materials, and furnishing, but also of the layout and the relationship between the interior spaces. Howedy (2006) highlights the important role of the interior designer during the design process, and his/her impact on the general objectives of architectural project, since the presence of the interior designer in the first phase of the design process saves a lot of time and money. However, she specifies that their role is only to furnish and finish interior spaces, but not to design a layout. Haddad (2013) also emphasizes on the trans-disciplinary approach between the interior designer, architect, and the client in the design process from the beginning to end. Moreover, Husseiny (2017) confirmed in his study that the designers and residents have to work together to solve design problems.

\subsection{Tangible and Intangible needs}

Tangible needs - that were considered in this study - are the functional requirements of the layout that affect the physical comfort of the occupants. On the other hand, the intangible needs are the psychological requirements that are related to the aesthetic values and cultural and social factors. A successful layout should achieve both tangible and intangible needs (Fig.1). Studies in Egypt do not focus on the occupants' needs in their residential interior spaces.

Baseony (2009) identifies human needs in the contemporary Egyptian residences, linking them to physical, social, and psychological factors. She claimed that the aesthetic aspects of a residence are met when these factors are achieved. Also, Taqtaq (1999) explains the human factors in residential architecture by presenting archeological models of Egyptian and Syrian residential architecture. She stressed that the cultural aspects, as well as, heritage, religion, and traditions, have the greatest impact on a residence's design. On the other hand, Fuller (2017) confirms that researches on housing consistently show that markets and policies have a strong influence on the places and ideas that make up a house. This confirms the opinion mentioned previously about the tendency of the constructional companies to control the designs and spaces to gain high profits. Also, Yunus (2016) concluded that constructional companies focus in their advertisements mostly on peoples' esteem needs which comprise ones' luxury and prestige, but do not express the functional needs of the interior spaces.

This study will find preferences that will help construction companies build GCs with repeated units. In the case of designing private houses, the problem of architectural harmony between neighboring buildings will arise. Kesseiba (2015) suggested how to achieve harmony in spite of variations within the new emerging housing pattern.

\subsection{Methodology}

The methodology of this study is based on observation and an analytical field study of different layout residences within GCs in Sheikh Zayed, $6^{\text {th }}$ of October City which belong to two types of Egyptian GCs: luxurious and moderated GCs (El Sayed, 2016, 5). A survey is used as a tool for collecting information. This survey consists of a group of 106 occupants who represent 106 families. They live in 106 different models of residential units with different layouts. This category of families belongs to class A of the Egyptian society. The demographic information of these families is the following: $4-5$ family members, parents aged between 35 and 55 , and children under the age of 25.

The survey was conducted via social media in April 2019. Then, the results were analysed and interpreted using "Google Survey" to identify the interior design preferences that can maximize the occupants' satisfaction. The questionnaire included 28 multiple choice questions based on four main points that measure the occupants' satisfaction about tangible and intangible needs as following (Fig 1):

- Layout and circulation: The two main types of layout designs that will be discussed in the questionnaire are complex plan (Fig. 2) and longitudinal plan (Fig. 3) they will express the organic theory's meaning "Building grows from inside outward". This meaning will be explained through the relationship between the interior spaces, circulation, paths' lengths, and variety. The lengths of the paths measure the physical comfort, and the variety gives the option to choose the direction of the movement between private and service places. Abd-Elatif (2018) proved the negative effects of unsuitable circulation on the comfort and ability to organize the time for housewives. 
- Adequacy of interior spaces: Spaces should be adequate to the function they are used for, which is to accommodate all types of furniture needed for specific functions. Studies confirm that the presence of interior spaces that allow entertainment in the residential unit shows the success of the unit design (Baseony, 2009). Therefore, it is agreeable to add such spaces that may be either an extra room, in the case of multi-level residences, or a corner, in the case of one-level apartments

- Openings: A good view - which is considered one of the most important facilities in the GCs - is an advantage of a window in the right position. In addition, it has a functional role of providing the interior spaces with daylight and aeration. Doors and other indoor openings, that connect the interior spaces to each other, should be put in a place that provides a welcoming feeling and the best view of the space. Openings help provide the best options for the furniture's layout (Fig. 4). Kooshali, A. (2015) confirms that what distinguishes villas from apartments within buildings is the enjoyment of green elements. Lee, S. (2017) asserts that openings that provide green views, natural light, and ventilation, are preferred the most. Another questionnaire was done at the same time as the occupants' survey; 37 Egyptian interior designers were asked to choose the best furniture layout - according to the opening's position - and 35 of them chose plan (b) (Fig. 4).

- Flexibility: It is the ability to change interior space functions according to ever-changing needs, without making major architectural adjustments - like demolition or building. It is also the ability to change the furniture layout within the same space (Tannous, 2013). Achieving flexibility provides functional needs and psychological comfort.

Based on the survey results, two residences' interior architecture will be analysed according to the same points of the questionnaire, showing the changes that the residences made before living in these units. This will help clarify how the constructional companies fulfil the occupants' needs based on their opinions.

\begin{tabular}{|c|c|c|c|c|c|}
\hline \multicolumn{2}{|c|}{ Interior requirements } & \multirow[t]{2}{*}{ Tangible needs } & \multicolumn{3}{|c|}{ Intangible needs } \\
\hline & & & Aesthetic values & Psychological comfort & Privacy \\
\hline \multirow{2}{*}{$\begin{array}{l}\text { Layout and } \\
\text { circulation }\end{array}$} & Longitudinal plan & & & Forced to move in one direction & - \\
\hline & Complex plan & Physical comfort & better view & $\begin{array}{l}\text { Variable pathways, which give the choice to } \\
\text { choose the movement's direction }\end{array}$ & Privacy \\
\hline \multicolumn{2}{|c|}{ Openings (doors and windows) } & $\begin{array}{l}\text { - Daylight and } \\
\text { aeration } \\
\text { - Better furniture } \\
\text { layout }\end{array}$ & $\begin{array}{l}\text { - Balance when } \\
\text { designing the } \\
\text { room } \\
\text {-Better furniture } \\
\text { layout choices }\end{array}$ & better view & Privacy \\
\hline \multirow[t]{2}{*}{ Flexibility } & $\begin{array}{l}\text { Variation of the rooms' usage } \\
\text { with different functions }\end{array}$ & \multirow[t]{2}{*}{ Function } & & Psychological comfort and satisfaction & \\
\hline & $\begin{array}{l}\text { Variation of furniture layout in } \\
\text { a room }\end{array}$ & & & & \\
\hline \multirow{2}{*}{$\begin{array}{l}\text { Adequacy of } \\
\text { interior } \\
\text { spaces }\end{array}$} & Furniture & \multirow[t]{2}{*}{ Physical comfort } & & \multirow[t]{2}{*}{ Psychological comfort and satisfaction } & \multirow[t]{2}{*}{ Privacy } \\
\hline & Storage & & & & \\
\hline
\end{tabular}

Fig 1: Interior requirements included in the study and their relation to the tangible and intangible needs.

(Source: by researcher)

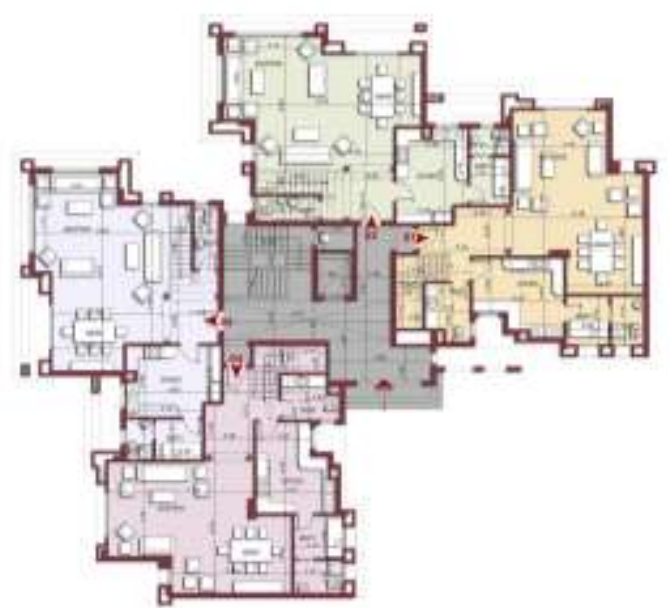

Fig. 2 (a): The ground floor of the building consists of four duplexes.

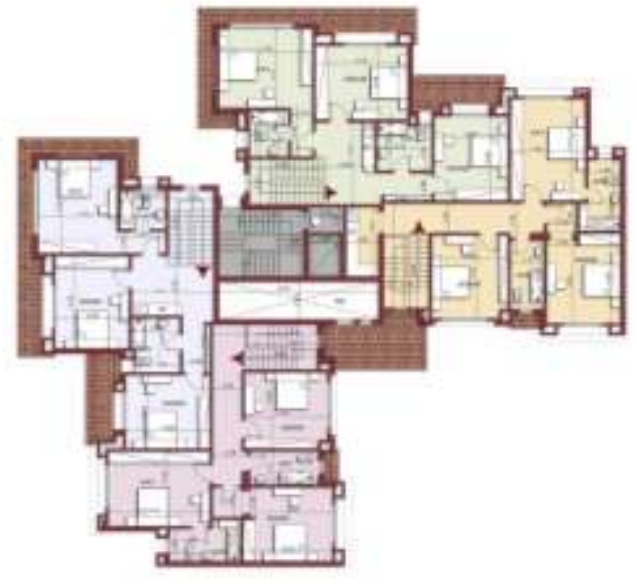

Fig. 2 (b): The first floor of the building. 


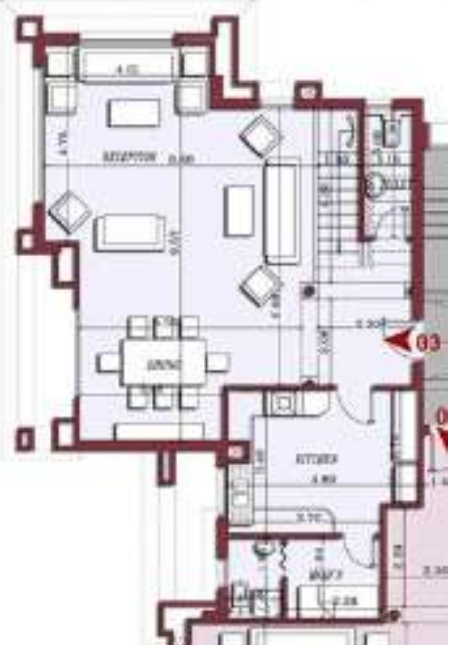

Fig. 2 (c): The ground floor - model 03

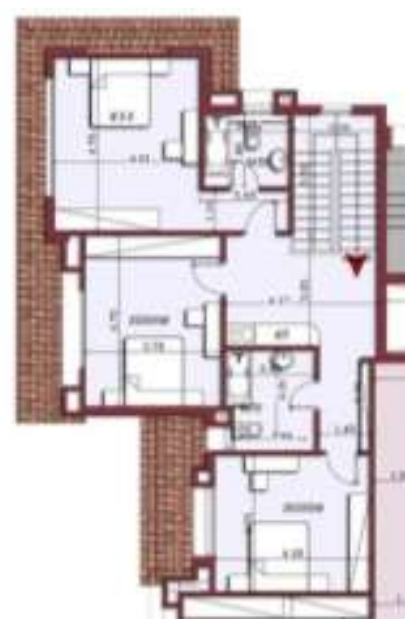

Fig. 2 (d): The first floor - model 03

Fig. 2 (a, b, c, d): Duplex apartment - Casa Allegria Compound - Royal Garden, 6th of October City (Source: Casa Allegria compound flyers)

This is an example of a complex plan of a residence. It shows the various pathways that the occupant can use from the entrance. The entrance is welcoming. All the rooms benefit from the view in the best way possible, due to the location of the residences in the building. This example reflects the design that grows from inside outward.

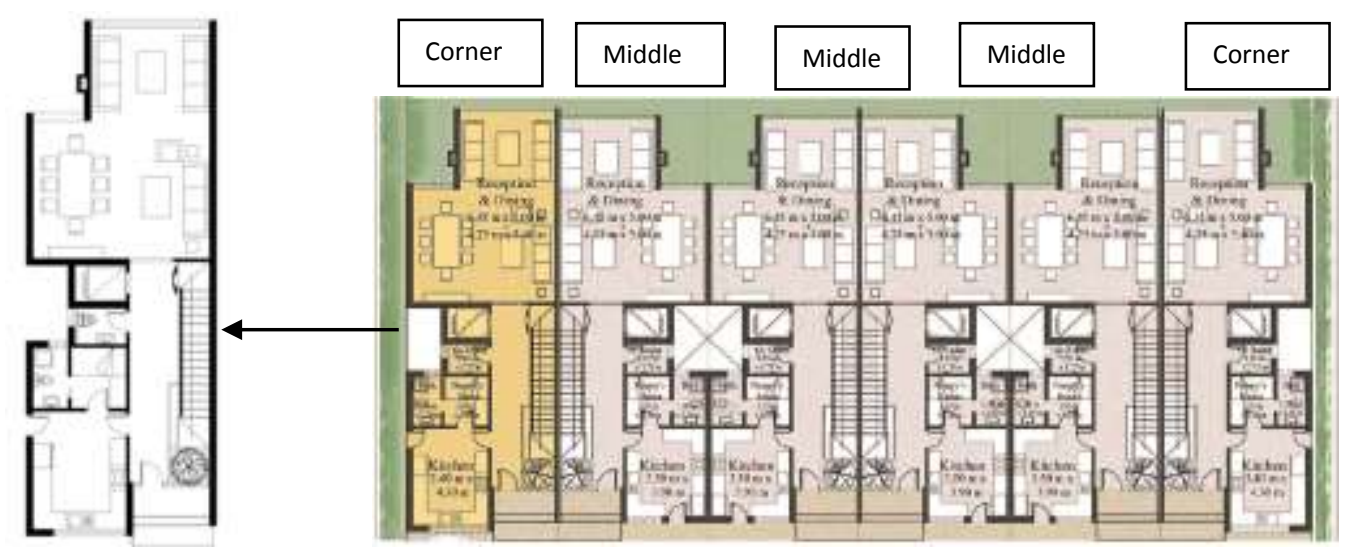

Fig. 3 (a): The ground floor of the townhouse

Fig. 3 (b): The ground floor of the building.

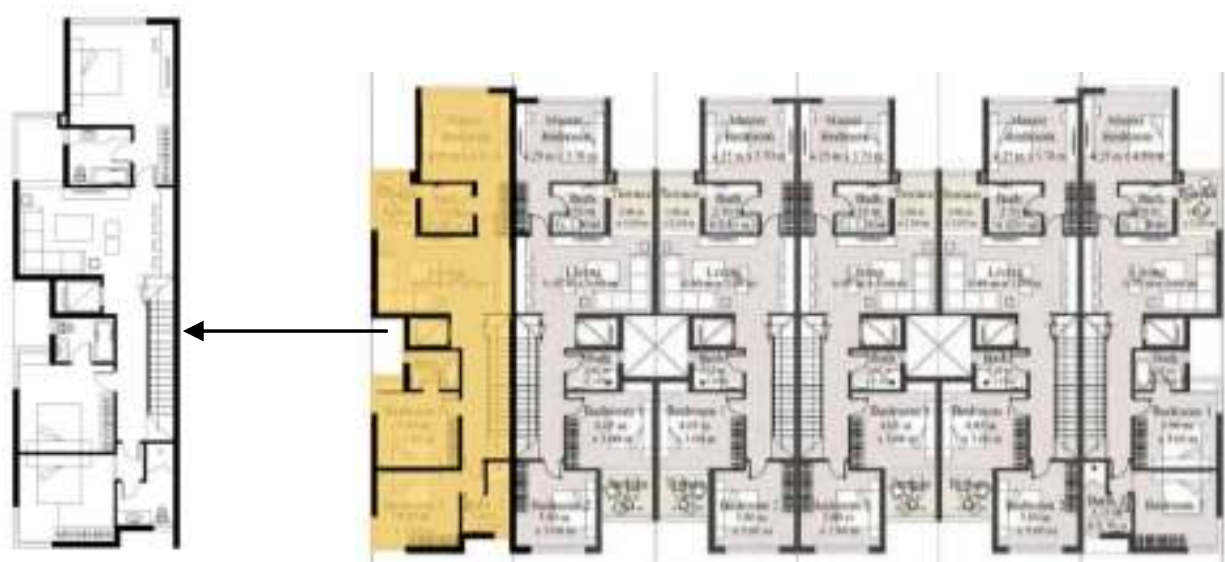

Fig. 3(c): The first floor of the townhouse

Fig. 3 (d): The first floor of the building

Fig. 3 (a, b, c, d): Townhouse - Palm Park Compound, 6th of October City. (Source: Palm Park compound flyers)

This is an example of a longitudinal plan of a residence. It shows the long pathways from the entrance to the formal living area, which force the occupants to walk inonly one direction by the service area. Windows limit the view because of their position, especially in the family living area in the middle model. 


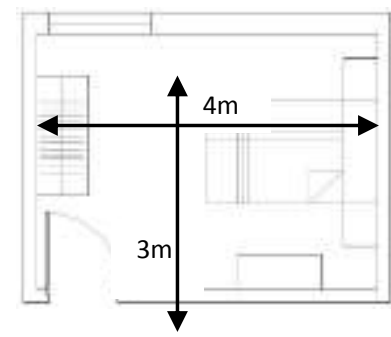

(a)

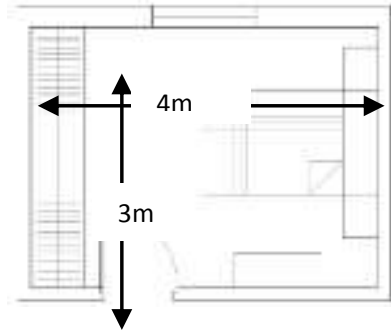

(b)

Fig. 4 (a, b): These are examples of how the position of the opening affects the furniture layout. In the layout (a) the positions of the door and window do not allow much space for a large closet. Also, the window doesn't allow the best view and aeration. In the layout (b) the position of the door and window allow much better space for the closet, view, and aeration, in addition to achieving a balance to the design of the wall. These two layouts were shown to 37 Egyptian interior designers, 35 of whom chose layout (b) as the better layout.

(Source: by researcher)

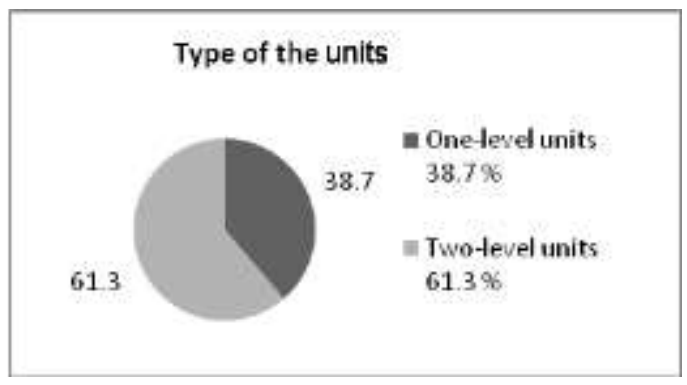

(a)

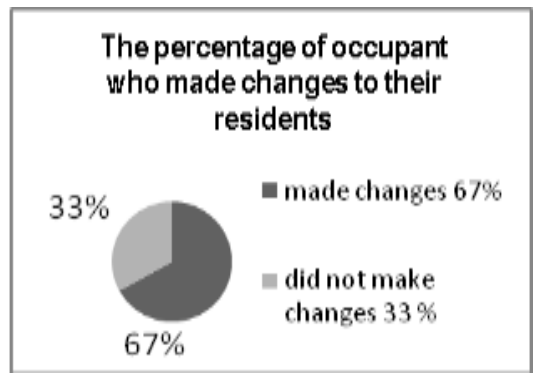

(b)

Fig 5: (a) The types of units included in the survey, (b) the percentage of the occupants who made changes to their units before living in them (Source: by researcher)

\subsection{Findings}

The research includes $38.7 \%$ apartments and $61.3 \%$ two-level residential units, varying between duplexes, townhouses, and standalone villas. The survey shows that $67 \%$ of the occupants made major changes to their residences (Fig. 5). All of them moved to their residences after 2000 (Fig. 13).

\subsection{Layout and circulation}

$75.5 \%$ of occupants prefer complex plans and $56.6 \%$ believe that long passages are not comfortable, nevertheless; $30.2 \%$ of the residential units contain long pathways (Fig. 6).

$22.6 \%$ of the bedrooms lack acoustic privacy, as they are affected by the noises electric apparatuses make. Moreover, $6.6 \%$ lack visual and acoustic privacy in their bedrooms.

$51 \%$ enjoy privacy in their family living area, while another $7.7 \%$ do have privacy but their living rooms are annoyingly far from the service area. $41.3 \%$ of the living rooms completely lack privacy (Fig. 7).

This lack of privacy is due to the location of the rooms near to the service area. But actually, $61.1 \%$ of the occupants of multi-level units prefer the family living area to be in the ground floor, due to easy usage and access to the service areas, so the circulation should keep its privacy (Fig. 8).

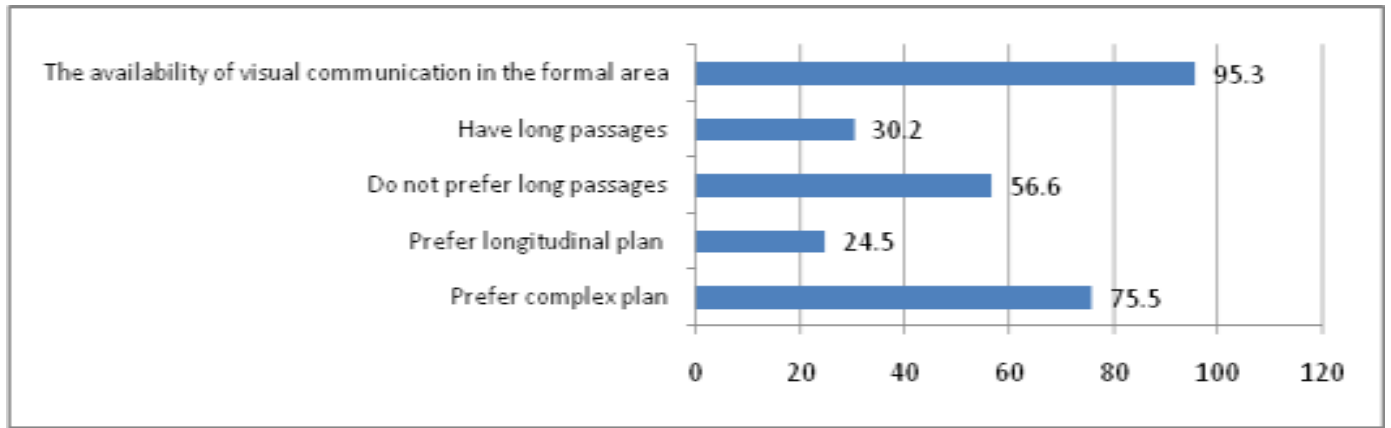

Fig. 6: Layout and circulation's occupants' preferences.

(Source: by researcher) 


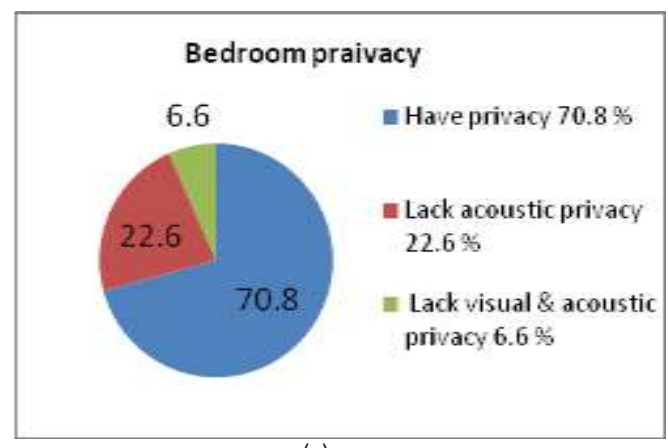

(a)

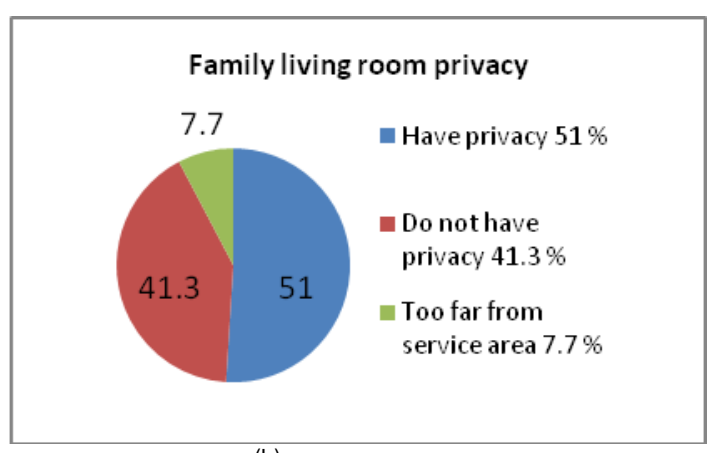

(b)

Fig. 7: Occupants' opinion about privacy (a) in the bedrooms and (b) in the family living area.

(Source: by researcher)

\begin{tabular}{|l|c|c|c|}
\hline Layout and circulation & $\%$ of preferences & Tangible need & Intangible need \\
\hline Prefer complex plan & $75.5 \%$ & $\begin{array}{c}\text { Physical comfort with the } \\
\text { variable - short pathways }\end{array}$ & $\begin{array}{l}\text { Privacy - psychological comfort (having } \\
\text { the option of choosing a pathway) }\end{array}$ \\
\hline Prefer longitudinal plan & 24.5 & Limited pathways & Forced to walk in one direction \\
\hline Do not prefer long paths & 56.6 & Physical comfort & Privacy - psychological comfort \\
\hline $\begin{array}{l}\text { Have long passages } \\
\text { Visual communication in the } \\
\text { formal/family living area }\end{array}$ & 30.2 & $\begin{array}{c}\text { Narrow passages between } \\
\text { the rooms }\end{array}$ & $\begin{array}{c}\text { Giving the impression of being a narrow } \\
\text { and small area }\end{array}$ \\
\hline
\end{tabular}

Fig.8: The relation between the layout and the tangible and intangible needs.

(Source: by researcher)

\subsection{Adequacy of Interior Spaces}

$67.9 \%$ of the occupants believe that the bedroom spaces are not adequate for furnishing all their requirements. This problem was one of the reasons why they made architectural changes. When the occupants were asked which pieces of furniture they did not find space for, their responses varied from a book shelf or a desk to a sofa.

$80.2 \%$ of the occupants indicated that there were insufficient storage spaces in the residences. $32.5 \%$ of them added spaces, while the rest remained in need. Only $19.8 \%$ said that there were enough spaces in the original design.

$83 \%$ of the residential units lack space for an extra area that can be used for additional activities. $22.6 \%$ added that space later, while $41.5 \%$ still would like to add it, and only $18.9 \%$ expressed no need for this space (Fig. 9). This need for space shows that construction companies do not take into consideration the occupants' activities.

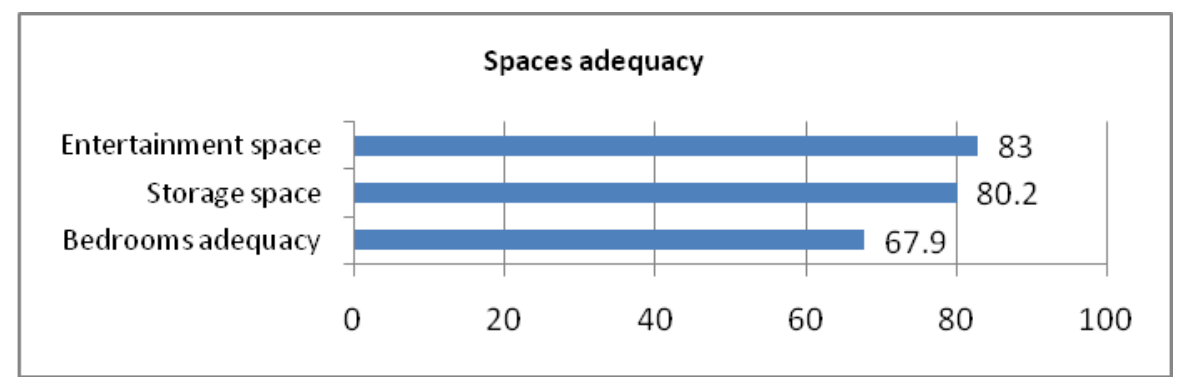

Fig. 9: The opinion of the occupants about the adequacy of the interior spaces, showing the insufficient rooms. (Source: by researcher)

\subsection{Openings}

$50 \%$ of the occupants believe that maintaining a good view is the greatest advantage of distinctive housing. $45.2 \%$ of the occupants said that windows in the corner of the rooms are inconvenient as they obstruct the view, lighting, and aeration. However, $59.4 \%$ of the residential units have a window in the corner of at least one room.

Only $17 \%$ chose the window in the corner, because it gives privacy. $37.7 \%$ do not feel that there is a difference between the windows' position. Also, occupants show their opinions on the openings that affect the furniture layout (Fig. 10). 


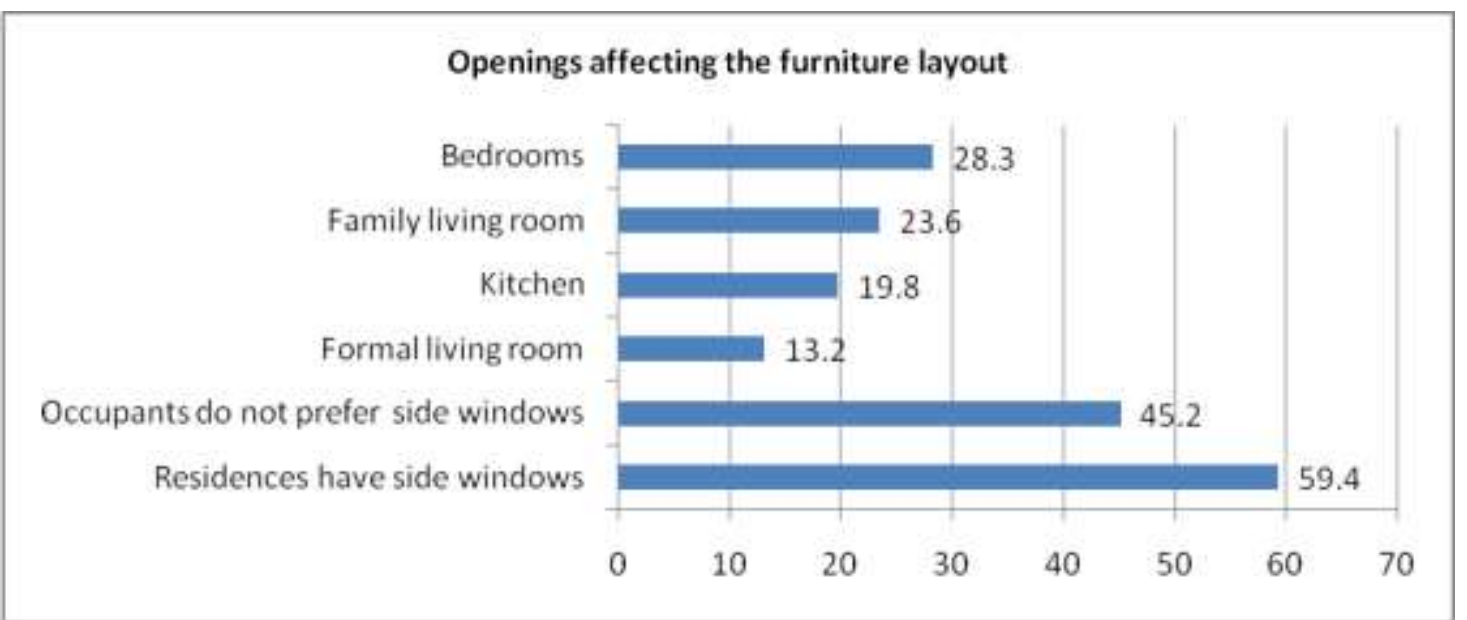

Fig. 10: Occupants' opinions on the openings' positions that affect the furniture layout in a negative way. (Source: by researcher)

\subsection{Flexibility}

$15.1 \%$ of the total occupants think they have the flexibility to change rooms' functions, and $26.4 \%$ of them think that they cannot change anything (Fig. 11). It was noted, that the occupants of one-level units think they can make more changes than the occupants of multi-level units (Fig.12) However, they stated that they will need more modifications when their children grow older.

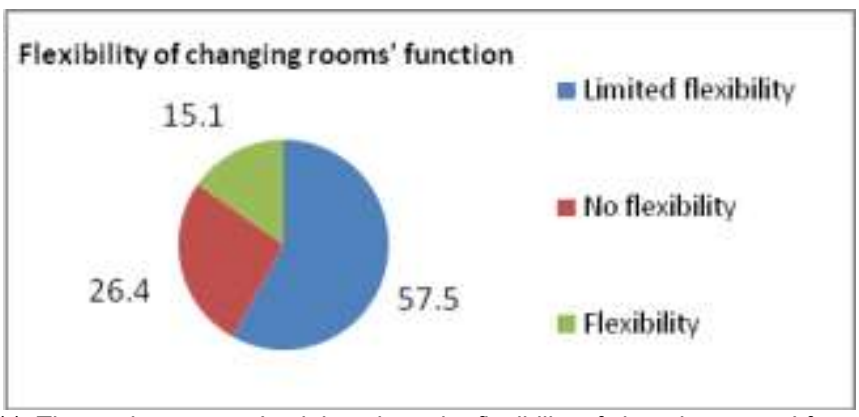

Fig. 11: The total occupants' opinion about the flexibility of changing rooms' functions.

(Source: by researcher)

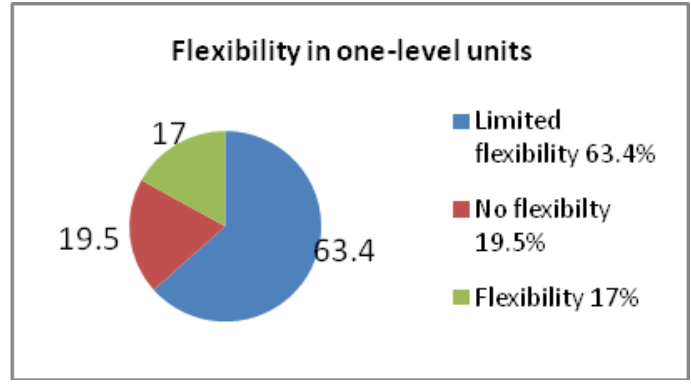

(a)

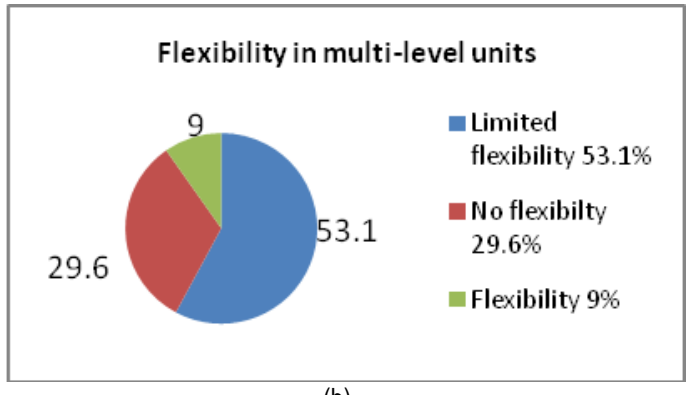

(b)

Fig. 12: The occupants' opinion about the flexibility of changing the rooms functions.

(Source: by researcher) 


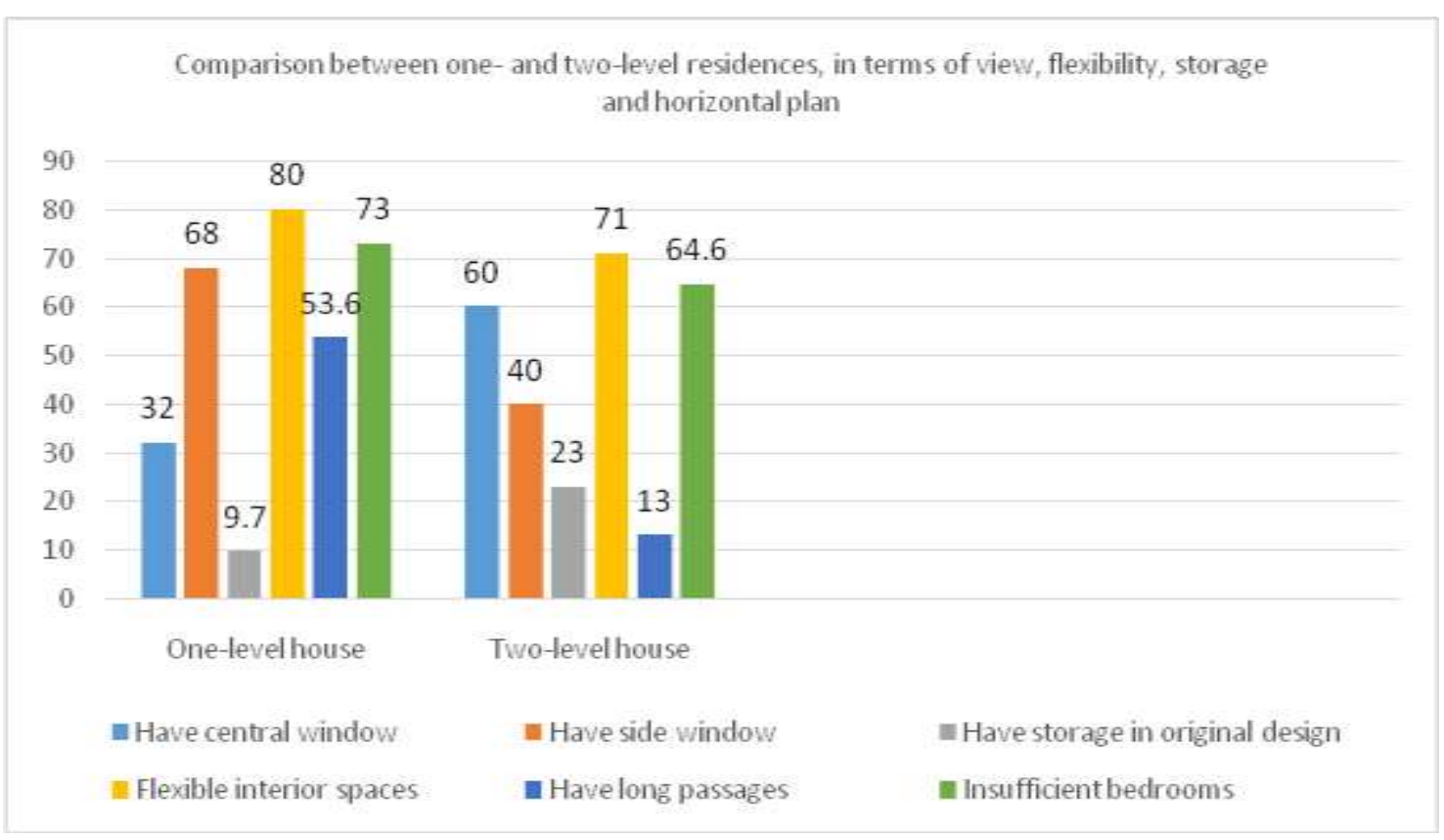

Fig. 13: Comparison between one- and two-level residences, in terms of view, flexibility, storage and horizontal plan (Source: by researcher)

\subsection{Model analysis before and after modification:}

Two residences' layouts will be analysed to show the architectural renovations, which were made according to the residents' requirements.

\subsubsection{Reem residence compound, twin villa, total area before modification: $231 \mathrm{~m}^{2}$, the ground floor area $98.80 \mathrm{~m}^{2}$, the first} floor area $104.34 \mathrm{~m}^{2}$, the roof $27.95 \mathrm{~m}^{2}$.

This model belongs to a family of four; the father is a 54 year old surgeon, the mother is a 43 years old professor, and the two boys are 12 and 13 years old.

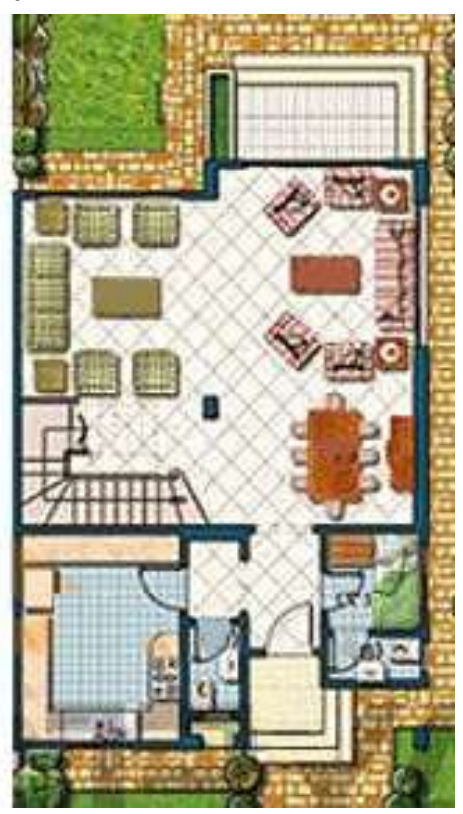

(a) the ground floor before the modifications (Source: Reem residence compound flyers)

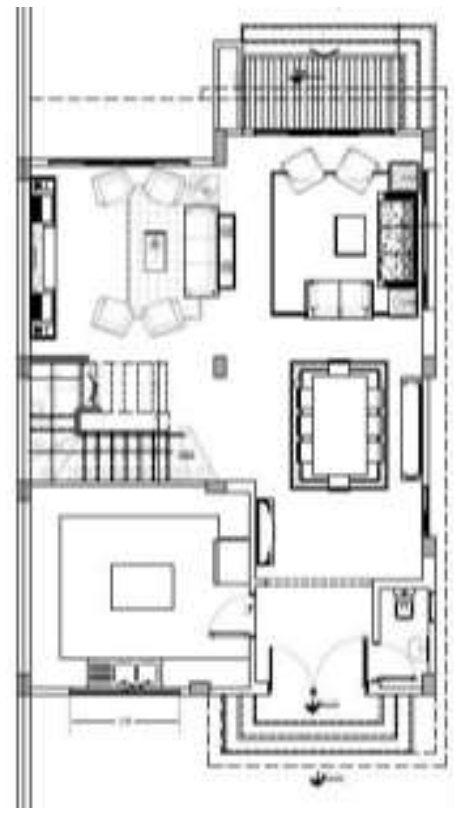

(b) the ground floor after the modifications (Source: by researcher)

Fig.14 $(a, b): I n$ the ground floor, the guest bathroom near the kitchen was removed to widen the kitchen. the maid room was replaced with a guest bathroom. In addition, the entrance was expanded towards the outside which made it more luxurious and welcoming, and widened the formal living area. They also added a storage room under the staircase. However, part of the aesthetic aspect was missing because of the column in the middle of the hall, which was to give the place a better sense of spaciousness, if not present. 
The modifications were needed to obtain tangible needs: spaciousness and storage spaces. In addition to obtaining, the intangible needs: luxury, aesthetic values, and privacy.

These requirements were fulfilled by expanding the kitchen, as well as the main entrance to make it more luxurious and welcoming (Fig. 14). The master bed room was moved to the roof which allowed it to become larger and it was replaced with the living room with a kitchenette (Fig.15, 16). It is important to note that architectural changes that affect the façade were not allowed due to the compound's rules and regulations.

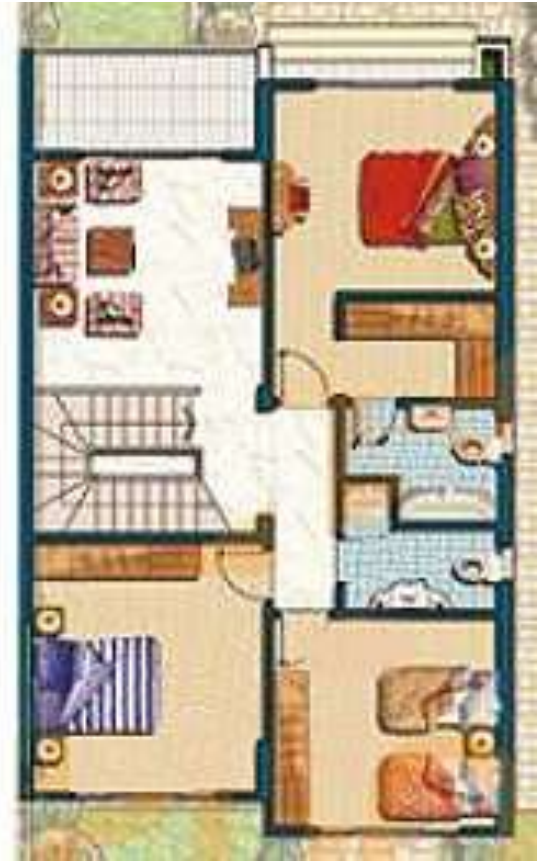

(a) the first floor before the modifications (Source: Reem residence compound flyers)

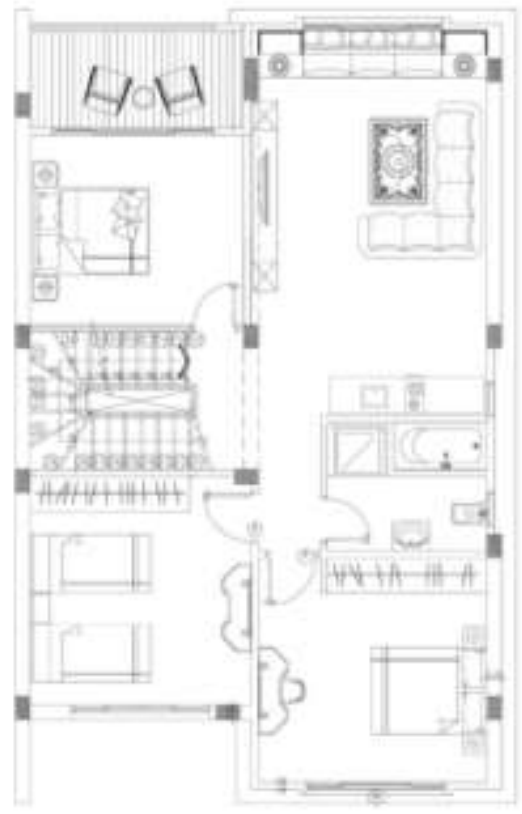

(b) the first floor after the modifications (Source: by researcher)

Fig.15 (a,b): The master bed room was moved to the roof floor, and was replaced with a family living area. Part of the master bathroom was removed to widen the living area, and the bathtub was added to the bathroom next to it by shifting the wall.

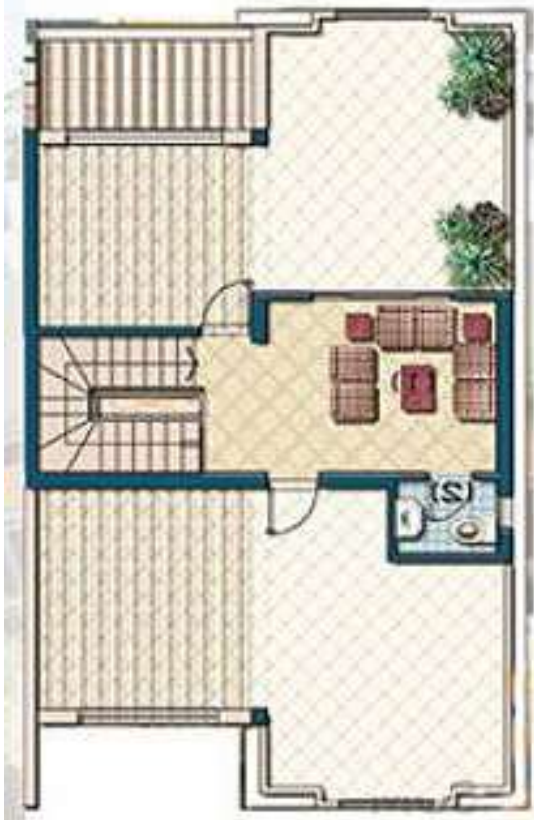

(a) the roof before the modifications (Source: Reem residence compound flyers)

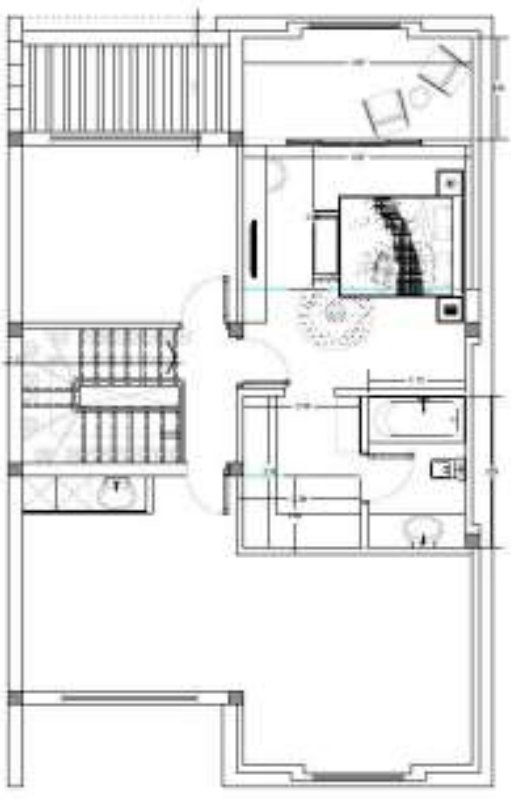

(b) the roof after the modifications (Source: by researcher)

Fig.16 (a, b): The small living area became a master bedroom by making extensions from two sides to add a closet and a wider bathroom. 
4.5.2 Continental compound, twin villa, total area before modification: $391 \mathrm{~m}^{2}$, the ground floor area $131 \mathrm{~m}^{2}$, the first floor area $132 \mathrm{~m}^{2}$, the roof $128 \mathrm{~m}^{2}$.

This model belongs to a family of five: 50 year old father, 45 year old mother, one 16 year old girl, and 14 and 8 year old boys. This compound's company had lenient rules, so the family was able to extend the outside of the side façade. (Fig. 17, 18, 19) In this model, major changes have been done in the layout the staircase was demolished and rebuilt in the opposite direction to solve a number of problems related to space and privacy of the service areas. Also, obtain more private and luxurious bedrooms.

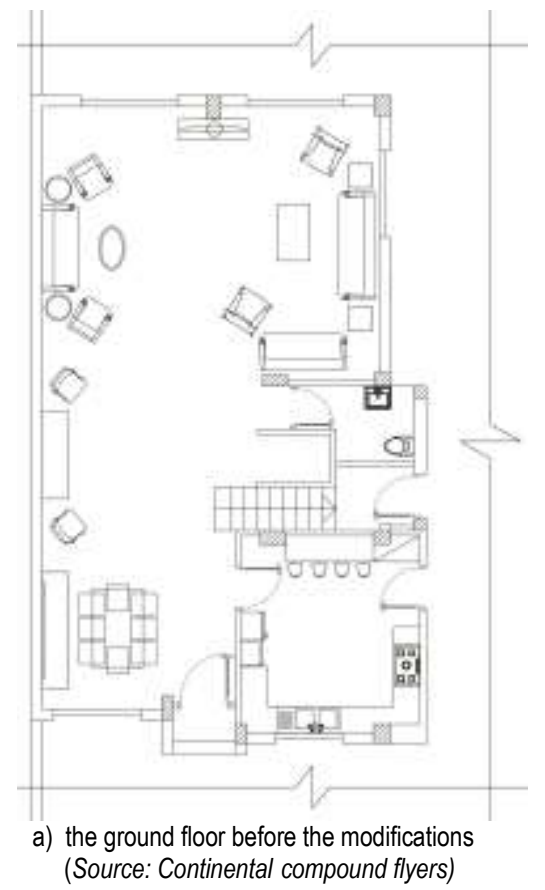

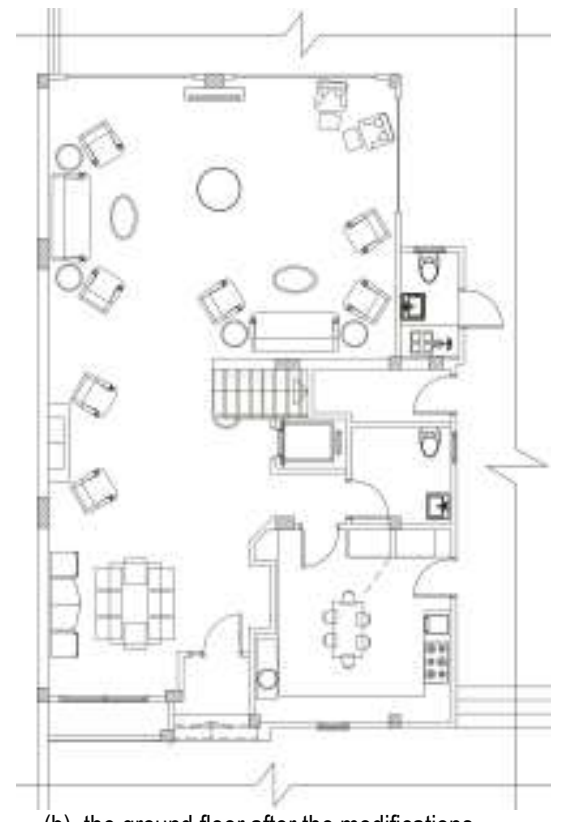

(b) the ground floor after the modifications (Source: by researcher)

Fig. 17(a, b): The guest bathroom was under the staircase - adjacent to the formal living area - and had no privacy. Two main modifications were done to solve this problem: 1) the staircase was demolished and rebuilt in the opposite direction which led to the relocation of the bathroom to the other side of the staircase, to have more privacy. The kitchen also gained privacy, by changing its door's position. 2) The outwards expansion towards the garden helped widen the kitchen, the guest bathroom, and the storage; in addition, an outdoors bathroom was added. Also, an elevator was added.
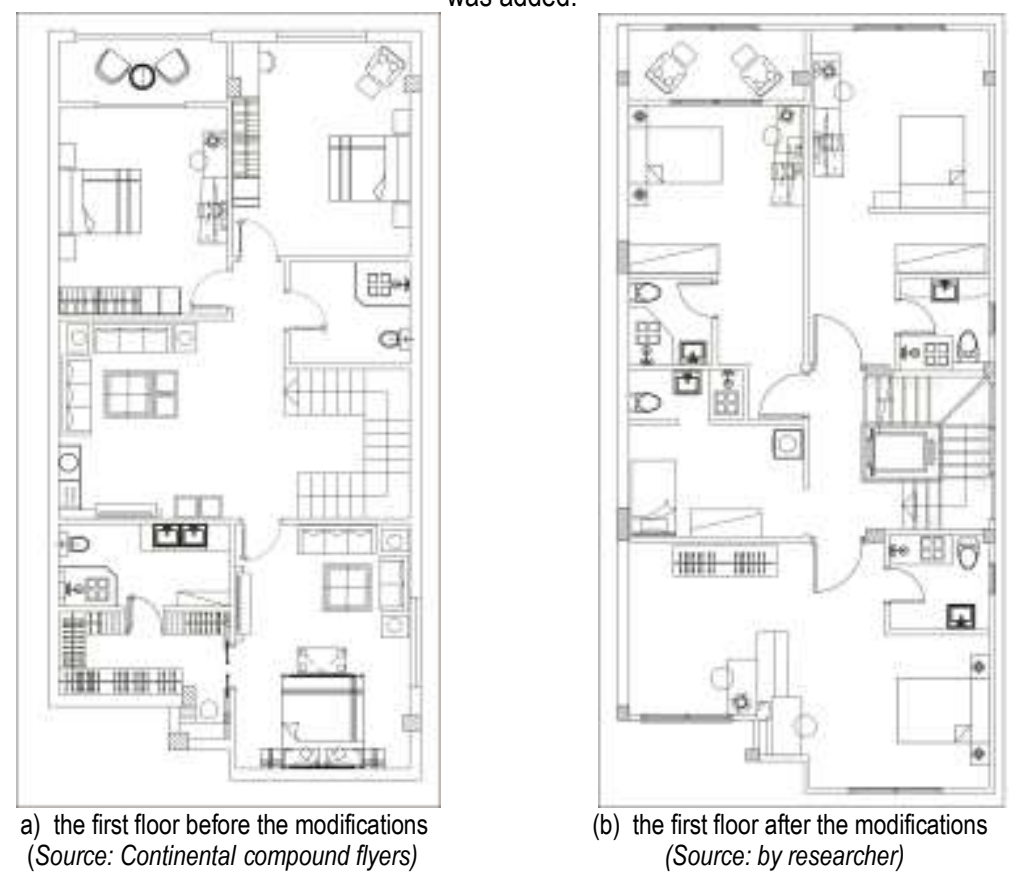

Fig. $18(a, b)$ : In the first floor the family living area was removed, in order to have three luxurious bedrooms and a maid room - each bedroom has its own private bathroom. 

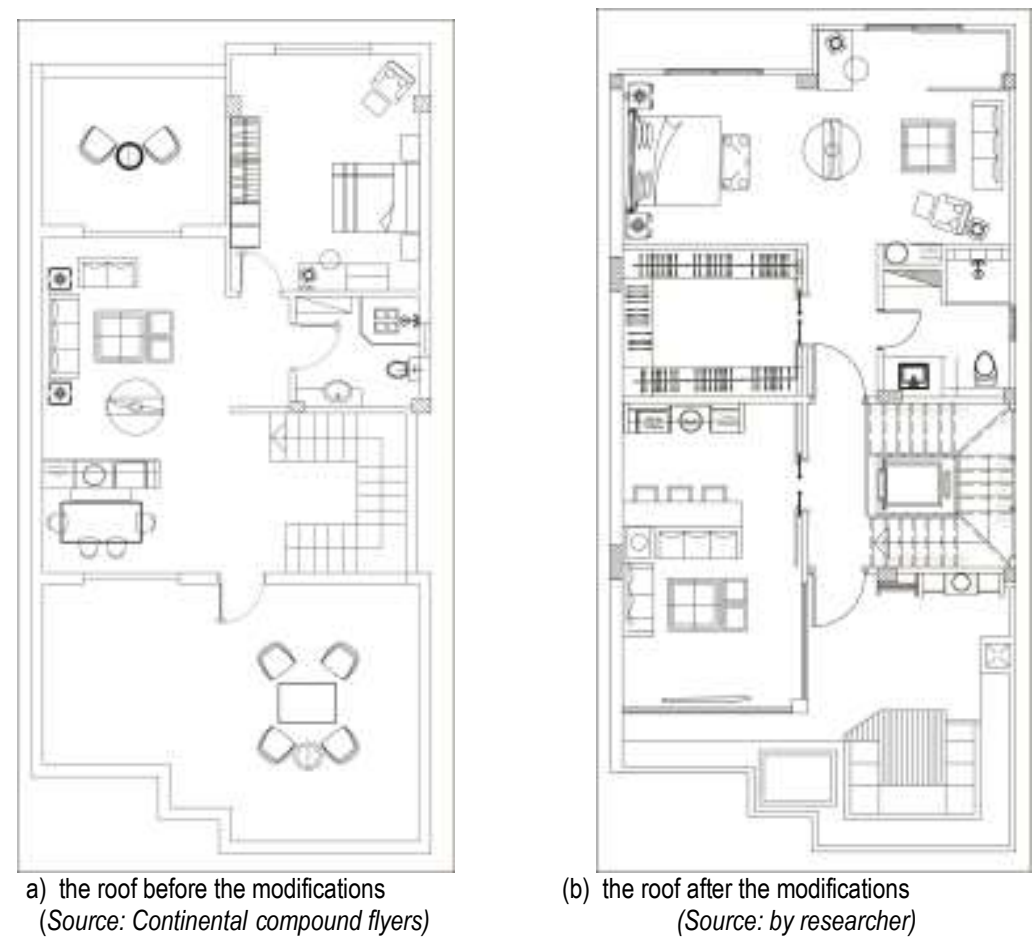

Fig. 19 (a, b): The master bedroom was moved to the roof to obtain privacy, luxury of furniture, spaces, and view.

\subsection{Discussion}

The high percentage of occupants who made changes to their residences shows that most residential units, provided by construction companies, do not fully meet the occupants' needs. The two units analysed above show that the adjustments were made to attain: a) spacious areas for bedrooms - particularly the master bedroom, living areas (with kitchenette), and kitchen, $b$ ) the addition of storage areas, and c) the modification of the main entrances. These adjustments were made at the expense of the balcony, maid room, bathroom, and garden. The expansion of the bedroom was preferred to be at the expense of the living areas, so that a dressing room can be added. However, these adjustments caused a great waste of time, effort, and money as some of the occupants' needs were not considered from the beginning of the design process. Based on this survey and analysis, residents' main preferences can be concluded.

\subsection{Layout and circulation}

After analysing previous models of the layout, it is clear that the complex design can meet the occupants' requirements. This layout allows the division of the residence into three areas: service area, formal living area, and family living area with bedrooms. This division should be done in a way that preserves the privacy of each area. Therefore, the family living area should be placed in the center of all these areas to provide privacy and physical comfort. If a family living area is located in the first floor of a two-level unit, it is preferred to have a kitchenette in the corner.

Using the complex plan helps the layout of the house to provide convenient and varied pathways between the spaces. Circulation between the living area and the service area should not be interrupted by the formal living area or the main entrance of the house. Also, the living area should not interrupt the privacy of the bedrooms' zone - particularly the master bedroom. All the spaces should receive equal amounts of attention in terms of space and view.

It is important that the number of rooms is suitable for the size of the family that inhibits the residence. The questionnaire shows that the average number of family members in class $A$ is four (as confirmed by The Central Agency for Public Mobilization and Statistics. 2018). Therefore, they need at least three bedrooms.

\subsection{Adequacy of interior spaces}

Out of all the rooms in a residence, bedrooms lack space the most. Also, most residential units lack storage facilities - even multi-level residences. So, the availability of adequate spaces in rooms is demanded in order to fit all the furniture; the suggested area is at least $400 \times 300 \mathrm{~cm}^{2}$ (Fig. 4). In addition, storage spaces should be added to the residence, and their area depends on the area of the whole residence. It is agreed upon that adding an entertainment space that could either be an extra room, in the case of multi-level residences, or a corner, in one-level apartments, is preferable. 


\subsection{Openings}

The correct position of an opening will help meet the tangible needs, which are the adequacy of space, better furniture layout choices, day light, and aeration. In addition to, the intangible needs, which are better views and luxury. The main entrance of the residence takes a lot of attention from the occupant, in order to be luxurious and welcoming. Also, it is preferred for each interior space to have a welcoming entrance that provides the best view upon entrance - as long as no privacy is invaded. Furthermore, it is not preferred to put the door in the room's corner; rather, it should be distanced so that the entire side wall can be used. The window in the middle of the wall will allow natural lighting, ventilation (to the all the room's spaces equally), and a better view (Fig. 4). This also gives balance and symmetry, which are important principles when designing and decorating walls.

\subsection{Flexibility}

The flexibility of changing a room's function is a necessity when living in the same residence for many years. It can be achieved by accomplishing the previous points. Throughout life, the areas in a residence that need the most changing are the family living area and the bedrooms, when children and parents grow older. A good relationship between spaces can help make these changes more easily. For example, the position of the living area in the center of the residence helps join it to bedroom area or the formal area, as needed.

The correct position of the openings in an interior space helps increase the various choices for furniture layout. When observing (Fig. 4, b) it can be noticed that this location of the opening allows more space and there is no dead area behind the door for any piece of furniture like a library or closet of any size. This layout allows the usage of the entire wall area without blocking the door or obscuring the window.

\subsection{Conclusion and Recommendations}

These preferences can be summarised into three aspects. Firstly, is the need for privacy, especially visual privacy of the family living area, as a social aspect. Secondly, the benefit from the landscape views in all the spaces. Thirdly, the functional aspect is the provision of adequate space for furniture and storage. Notably, one-level apartments have these imperfections more than the two-level houses. The absence of these points from the design indicates that the role of the interior designer in residential projects is neglected, from the start of the design process. The dominance of the architect over the design process led to following the box design model. So, this study concludes that the interior designer's presence will help achieve design preferences that express the occupant's opinions in a better way. Using complex plan will help achieve various efficient solutions for the interior architecture layout rather than staying restricted to the box building.

The study recommends residential construction companies to consider occupants' preferences when designing residential buildings for class $\mathrm{A}$. Conducting surveys is highly recommended before starting the design process to reach the most integrated form, which will reduce the adjustments made by the occupants.

This study is the beginning of other future researches, which follow the same methodology, to find the occupants' ever-changing preferences.

\section{Acknowledgement}

The researcher would like to thank the University of October for Modern Sciences and Arts for its financial support for publishing in the conference.

\section{References}

Abd-Elatif A., Mansour R. (2018). Considerations of Home ergonomics and their relation to wife's self-management. Journal of Home Economics, volume 28 , Issue 4. ISSN 1110-2578

Baseony, H. A. (2009). The Contemporary Accommodation between the Tangible and Human needs. Master thesis, Faculty of Architecture, Cairo University.

Central Agency for Public Mobilization and Statistics. Statistical Yearbook (2018) - Population, issue 109https://www.capmas.gov.eg/Pages/StaticPages.aspx?page_id=5034

El Sayed, E. (2016). Residents Satisfaction at Gated Communities in Egypt, Case Study: New Cairo city in Greater Cairo Region (GCR). International Journal of Scientific \& Engineering Research, Volume 7, Issue 4, April-2016. IJSER@2016. http://www.ijser.org ISSN 2229-5518

Fuller, M. G. (2017). Great spatial expectations: On three objects, two communities and one house. Current Sociology Monograph. 2017. Vol.65(4) 603-622. DOI: 10.1177/0011392117694071. journals.sagepub.com/home/csi. SAGE

Haddad, H. (2013) Research and Methodology for Interior Designers. Procedia - Social and Behavioral Sciences 122 (2014) 283 - 291. 2nd World Conference on Design, Arts and Education DAE-2013.

Howedy, D. R. (2006).The Role of the Interior Designer in the Design Process and its Impact on the General Objectives of Architectural Projects, Applied Study on Selected Models of Architecture. Master thesis, Faculty of Architecture, Cairo University. 
Husseiny, A., Abdelkader, A. (2017). The Impact of Flexibility on Residential Buildings in Egypt. World Academy of Sciences, Engineering and Technology. International Journal of Civil Environmental, Structural, Construction and Architectural Engineering Vol: 11, No: 4, 2017. scholar.waset.org/1999.3/10007429.

Kesseiba, K. (2015). Cairo's Gated Communities: Dream homes or unified houses. Procedia - Social and Behavioral Sciences 170 (2015) 728 - 738.

Kooshali, A., Parvisi, R., Azeri, A. (2015). A comparative Study on the Effect of Nature on Satisfaction with Residence at Detached Houses (Single Unit) and Residential Building Complexes (Apartment). Procedia - Social and Behavioral Sciences 201 (2015) $243-254$.

Lee, S., Alzoudi, H. (2017). The Effect of Interior Design Elements and Lighting Layouts on Prospective Occupants' Perceptions of Amenity and Efficiency in Living Rooms. Sustainability 2017, 9, 1119; doi: 10.3390/su9071119. www.mdpi.com/journal/sustainability

Obied, M. E. (1986). Social Development in Egypt and its Impact on Contemporary Residence, Studies in the Development of Plans in Cairo. Master thesis, Faculty of Architecture, Cairo University.

Samy, O., (1968). Theories of Organic Architecture. United Colors Printing Est., Cairo, Egypt.

Tannous, W., Almohana, Z., Fakoush, O., (2013). Design Flexibility as one of the Most Important Criteria for Economic Housing. Damascus University Journal of Engineering Sciences, Damascus University, Volume 29, Issue 1.

Taqtaq, J. M. (1999). The human Factors in Residential Architecture, Applied Study on Selected Models of Egyptian and Syrian Architecture. Master thesis, Faculty of Architecture, Cairo University.

Wahbe, M. (2011). Theory of Interior Architecture. 2ed volume.ISBN: 2008/24232.

Yunus, N., Kasim, Z. (2016). Hierarchy of Needs in Residential Advertisements. Journal of Language and Communication, 3(1), 107-121 (2016). Faculty of Modern Languages and Communication, University Putra Malaysia. ISSN: 2289-649X 